\title{
PERBANDINGAN BRAND EQUITY PRODUK SHAMPOO MEREK SUNSILK DENGAN MEREK PANTENE
}

\author{
Ida Ayu Raras Aristyani \\ Ni Nyoman Kerti Yasa \\ Jurusan Manajemen Fakultas Ekonomi Universitas Udayana \\ Email: manrai_kerti@yahoo.co.id
}

\begin{abstract}
Abstrak
Penelitian ini memiliki tujuan untuk mengetahui perbedaaan brand equity beserta elemen-elemennya antara produk shampoo merek Sunsilk dengan Merek Pantene. Teknik analisis data yang digunakan adalah uji beda mean dengan sampel berpasangan. Berdasarkan hasil penelitian, ditemukan bahwa tidak terdapat perbedaan ekuitas merek antara shampoo Sunsilk dengan Pantene. Dari empat dimensi ekuitas merek, hanya satu yang berbeda, yaitu brand perceiverd quality. Oleh karena itu, ke depan shampoo merek Sunsilk harus lebih fokus kepada peningkatan kualitas produknya dengan cara inovasi dalam aroma, kandungan bahan, dan mutu keseluruhan sehingga mampu selalu berada pada posisi top brand bersama-sama merek Pantene.
\end{abstract}

Kata kunci: Ekuitas Merek, Kesadaran Merek, Asosiasi Merek, Persepsi Kualitas Merek, Loyalitas Merek.

\begin{abstract}
The objectives of the study were to know the difference in brand equity and its elements between shampoo products with brand Sunsilk and Pantene. The data analysis technique used was the mean difference test with paired samples. Based on the results of the study, it was found that there is no difference between brand equity Sunsilk with Pantene. the four dimensions of brand equity, just a different one, namely brand perceived quality. Therefore the next shampoo brand Sunsilk should be more focus on the improvement of the quality of its products by way of innovation in flavor, ingredients, and overall quality so as to always be in the top brand position together Pantene.
\end{abstract}

Keywords: Brand Equity, Brand Awareness, Brand Association, Brand Perceived Quality, Brand Loyalty.

\section{PENDAHULUAN}

Dalam era globalisasi ini, persaingan begitu ketat karena banyak produk sejenis yang beredar di pasaran. Karena itu arti sebuah merek (brand) menjadi sangat penting. Untuk bertahan di pasaran diperlukan sebuah merek (brand) yang akan menciptakan nilai tambah atas suatu produk. Darwing \& Wijoyo (2004) mengemukakan merek (brand) adalah nama dan identitas utama suatu produk atau jasa badan usaha, sehingga dapat dibedakan dari produk atau jasa sejenis yang ditawarkan oleh pesaing. Menurut Kartajaya (2004) merek (brand) merupakan nilai utama pemasaran. Semakin kuat merek produsen di pasar, maka semakin eksis pula merek tersebut, terutama dalam hal mendominasi kesadaran konsumen sehingga akan mengarahkan konsumen untuk mengkonsumsi produk tersebut. Pernyataan ini juga didukung oleh penelitian yang dilakukan oleh Mourad et al. (2011). Santoso \&
Resdianto (2007) yang menyatakan bahwa merek (brand) adalah salah satu aspek dari kekuatan dan keunggulan perusahaan dalam persaingan global. Merek yang sukses memberikan keuntungan kompetitif yang sangat penting untuk keberhasilan perusahaan (Fayrene \& Lee, 2011). Dengan demikian, merek (brand) saat ini tak hanya sekedar identitas suatu produk saja dan hanya sebagai pembeda dari produk pesaing, melainkan lebih dari itu, merek (brand) memiliki ikatan emosional istimewa yang tercipta antara konsumen dengan produsen. Pesaing bisa saja menawarkan produk yang mirip, tapi tidak mungkin menawarkan janji emosional yang sama. Pernyataan ini sesuai dengan penelitian yang dilakukan oleh Daulay (2006) dan Kartono (2007).

Merek yang baik dapat disebut memiliki ekuitas merek yang kuat. Menurut Durianto dkk. (2004) ekuitas merek (brand equity) merupakan aset yang dapat memberikan nilai tersendiri di mata pelanggan. 
Apabila brand equity-nya tinggi, maka nilai tambah yang diperoleh konsumen dari produk tersebut akan semakin tinggi pula dibandingkan merek-merek produk lainnya. Pernyataan ini didukung oleh penelitian yang dilakukan oleh Delgado-Ballester \& Munuera-Alemán (2004). Laboy (2007) mengemukakan bahwa merek dengan ekuitas yang tinggi akan dapat memaksimalisasi dan meningkatkan aliran kas secara konstan. Jadi, ekuitas merek telah menjadi fokus yang semakin penting untuk perusahaan (Schumann, 2004; Gupta \& Verma, 2008) serta menjadi isu penting dalam desain dan pengembangan perusahaan (Smith, 2007). Penelitian yang berkaitan dengan ekuitas merek (brand equity) sudah banyak dilakukan oleh Wood (2000), Pappu \& Quester (2008), Cuomo et al. (2009), Davis et al. (2009), Bodet \& Chanavat (2010), Kimpakorn \& Tocquer (2010), Rajat \& Chau (2011), Mourad et al. (2011), Sanyal \& Datta (2011), dan Pinar et al. (2012), serta Wang \& Li (2012).

Kartajaya (2004) menyatakan bahwa produkproduk dengan keterlibatan rendah (low involvement) memiliki ekuitas merek yang rendah karena banyaknya varian dan barang substitusi yang muncul di pasaran. Oleh sebab itu, dibutuhkan upaya-upaya dari produsen dengan produk keterlibatan rendah itu untuk dapat mempertahankan eksistensi mereknya di pasaran. Menurut Quarles (2009) merek dengan ekuitas merek yang kuat dapat mempertahankan pangsa pasar, menarik investor serta menangkis datangnya pesaing baru. Fenomena yang hampir mirip juga sudah pernah diteliti oleh Smith (2007).

Kekuatan merek terhadap keputusan pembelian konsumen mendorong lembaga-lembaga riset melakukan penelitian secara berkesinambungan untuk mencari dan memilih merek-merek terbaik pada berbagai kategori untuk memperoleh penghargaan (award). Di Indonesia, beberapa lembaga riset yang berkompeten untuk hal ini diantaranya Frontier untuk Indonesia Customer Satisfactions Award (ICSA), MARS untuk Indonesia Best Brand Award (IBBA), MarkPlus untuk Superbrand, Onbee Marketing Research untuk Word of Mouth Marketing (WOMM) Award, majalah Marketing yang bekerja sama dengan Frontier Consulting Grup untuk Top Brand Award, dan lain sebagainya. Penghargaan-penghargaan tersebut merupakan kebanggaan bagi merek yang terpilih sebagai merek terbaik dan keberhasilan itu dapat dijadikan indikator keberhasilan dan prestasi sebuah merek di pasar. Jadi, penghargaan ini merupakan wujud pengakuan dari konsumen terhadap sebuah merek. Eugenia (2011) menyatakan bahwa logo Top Brand yang terpasang di kemasan memberikan pengaruh yang besar kepada konsumen untuk memilih produk tersebut. Sehingga peluang merek suatu perusahaan untuk dipilih konsumen akan semakin besar seiring keyakinan konsumen terhadap merek tersebut.

Salah satu produk yang menggunakan merek adalah produk shampoo. Shampoo adalah sejenis cairan, seperti sabun, yang berfungsi untuk meningkatkan tegangan permukaan kulit (umumnya kulit kepala) sehingga dapat meluruhkan kotoran. Kegiatan membersihkan kulit kepala dan rambut ini disebut keramas. Pada saat keramas, individu dianggap melakukan perawatan dengan mencuci rambut dan kulit kepala agar bersih dari minyak, debu, serpihan kulit dan kotoran lain yang menempel dirambut seiring aktivitas yang dilakukannya. Seiring perkembangan jaman, produk shampoo kian bervariatif. Ini semua dikarenakan permintaan konsumen akan jenis shampoo kian beragam, karena masalah rambut yang dimiliki tiap individu itu berbeda.

Wanita cenderung lebih memperhatikan penampilan, sehingga sangat memperhatikan penampilan rambutnya. Menyadari hal tersebut, banyak industri shampoo saling berlomba untuk memenuhi kebutuhan dan keinginan para konsumennya dengan menghasilkan produk shampoo yang dibutuhkan dan diinginkan bagi rambut konsumen (Santoso, 2010). Shampoo merupakan produk yang termasuk dalam kategori barang yang tidak tahan lama (non-durable goods), sehingga produsen harus melakukan strategi pemasaran tertentu untuk meningkatkan preferensi merek agar tercapai loyalitas merek pada konsumen. Hal ini sesuai dengan pernyataan Kotler (2007) mengenai barang yang tidak tahan lama (non-durable goods), yaitu barang berwujud yang biasanya dikonsumsi dalam satu atau beberapa kali penggunaan, sedangkan bila dikelompokkan menurut kebiasaan belanja konsumen, shampoo termasuk ke dalam kelompok barang convinience. Barang convinience adalah barang-barang yang biasanya sering dibeli konsumen, segera dan dengan usaha yang minimum. Menurut hasil penelitian yang dilakukan oleh Marthin \& Semuel (2007), produk shampoo dengan merek tertentu akan mempunyai konsumen dengan loyalitas tinggi bila terdapat kecocokan antara kualitas shampoo dengan karakteristik rambut yang dimiliki oleh konsumen. Konsumen shampoo yang loyal tidak akan bersedia ganti merek shampoo yang lain, karena shampoo dengan merek tersebut mampu memberikan hasil rambut seperti yang diharapkan. Selain itu, juga dinyatakan bahwa bila seorang konsumen telah loyal kepada suatu merek, maka mereka tidak akan dengan mudah berpindah ke merek lain, apapun yang terjadi dengan merek tersebut. 
Persaingan merek di Indonesia bisa dikatakan sangat ketat, begitu juga dengan produk shampoo. Hal ini dikarenakan terdapat banyaknya merek yang beredar di pasaran, tetapi hanya beberapa merek saja yang termasuk dalam kategori Top Brand. Top Brand mampu memberikan ukuran kesuksesan sebuah merek di pasar melalui tiga pengukuran dimensi, yaitu mind share (top of mind), market share (last usage), dan commitment share (future intention). Top Brand Index diformulasikan berdasarkan tiga variabel tersebut, dapat dikatakan ketiga variabel ini mampu memberikan gambaran tentang kondisi merek di pasar. Variabel pertama yaitu mind share, mengindikasikan kekuatan merek di benak konsumen. Market share menunjukkan kekuatan merek di pasar dalam hal perilaku pembelian aktual konsumen. Variabel ketiga, yaitu commitment share mengindikasikan kekuatan merek dalam mendorong konsumen untuk membeli merek tersebut di masa yang akan datang (Frontier Consulting Group, 2011).

Kota Denpasar merupakan pasar yang potensial bagi perusahaan shampoo atau distributornya dalam memasarkan produk. Hal ini mengingat kota Denpasar sebagai pusat perekonomian Provinsi Bali. Tiap individu pasti sangat membutuhkan shampoo untuk memenuhi kebutuhan kesehatan dan kebersihannya. Pada saat ini kebersihan adalah hal yang sangat penting untuk menjaga kesehatan. Semua kalangan masyarakat, baik yang dalam kategori ekonomi lemah hingga kategori ekonomi kuat, pasti menggunakan shampoo untuk membersihkan rambutnya. Kebutuhan konsumen akan shampoo merupakan kebutuhan yang tinggi. Saat sekarang ini jarang ditemui individu yang masih menggunakan air jerami, perasan daun mangkok serta santan untuk mencuci rambutnya, hal ini dikarenakan sudah banyak produk shampoo yang tentunya lebih praktis, serta dapat merawat rambut dengan hasil yang lebih baik.

Sesuai dengan hasil survey Top Brand yang dilakukan oleh Frontier Consulting Group dan Majalah Marketing beberapa produk shampoo yang bersaing di pasaran saat ini diantaranya Sunsilk, Pantene, Clear, Lifebouy, Rejoice, Dove, Zinc, Emeron dan Head \& Shoulders. PT Unilever Indonesia Tbk (UNVR) dan PT Procter \& Gamble Home Products Indonesia (P\&G) menguasai 90 persen pasar shampoo Indonesia, menurut data berbagai sumber yang dikompilasi Departemen Riset IFT. Pangsa pasar Unilever Indonesia mencapai 50 persen sementara pangsa pasar $P \& G$ Indonesia sebesar 40 persen (Monalisa \& Fitra, 2011). Kedua perusahaan ini merupakan perusahaan besar, yang sama-sama menawarkan produk perawatan pribadi- nya (toiletries product), seperti shampoo, dan pada tahun 2010 kedua perusahaan ini meraih predikat sama-sama sebagai perusahaan yang mencapai top brand.

Sunsilk dan Pantene adalah merek shampoo yang sudah dipercaya oleh sebagian besar masyarakat Indonesia. Di Bali khususnya di kota Denpasar shampoo ini pun sangat diminati dan sudah memiliki positioning yang kuat dibenak konsumen. Dilihat dari hasil survey dari Top Brand 2009 hingga 2012, kedua merek shampoo ini memperoleh Top Brand Index yang tinggi dibandingkan dengan pesaing-pesaing produk shampoo merek lainya. Pada tahun 2009 Top Brand Index Clear mengalahkan Top Brand Index Pantene, namun ditahun-tahun berikutnya Top Brand Index Pantene terus mengalami peningkatan. Persaingan yang ketat antara Pantene dan Sunsilk terlihat jelas dari perolehan Top Brand Index tersebut. Baik Sunsilk maupun Pantene sama-sama gencar mengiklankan produknya di televisi. Keduanya tak mau kalah dalam 'perang' iklan agar produknya menjadi top of mind di benak konsumen dan menjadi produk yang paling dikenal dipasar shampoo. Kedua produk tersebut menggunakan endoser iklan yang dikenal dan dianggap berpengaruh di masyarakat, yaitu Titi Kamal untuk Sunsilk dan Anggun C. Sasmi untuk Pantene, yang diharapkan dapat mempertegas asosiasi mereknya. Pemilihan endorser ini adalah salah satu strategi yang dapat digunakan bagi para pemasar agar produknya mendapat perhatian di masyarakat. Heruwati (2010) menyatakan celebrity endorser yang dianggap sebagai panutan bagi konsumen, mungkin lebih cenderung untuk mendorong kepercayaan dan dipercaya bagi konsumen, sehingga menjadi lebih mampu mempengaruhi niat pembelian, sikap dan perilaku konsumen. Berdasarkan latar belakang yang telah dipaparkan, maka yang menjadi pokok masalah dalam penelitian ini adalah apakah brand equity samphoo merek Sunsilk berbeda dengan Pantene. Tujuan yang hendak dicapai dalam penelitian ini adalah untuk mengetahui perbedaan brand equity (ekuitas merek) produk shampoo merek Sunsilk dengan Pantene (studi pada konsumen di kota Denpasar).

\section{LANDASAN TEORITIS DAN HIPOTESIS}

\section{Ekuitas merek (brand equity)}

Ekuitas merek menurut Kotler \& Amstrong (2008) adalah nilai dari suatu merek, menurut sejauh mana merek itu mempunyai loyalitas merek yang tinggi, kesadaran nama, kualitas yang diterima, asosiasi merek yang kuat, serta aset lain seperti paten, 
merek dagang dan hubungan saluran. Keller (2005) mendefinisikan ekuitas merek sebagai nilai yang secara langsung ataupun tidak langsung dimiliki oleh merek. Durianto dkk. (2004) mendefinisikan ekuitas merek sebagai seperangkat aset dan liabilitas merek yang terkait dengan suatu merek, nama, simbol yang mampu menambah atau mengurangi nilai yang diberikan oleh sebuah produk atau jasa baik pada perusahaan maupun pada pelanggan. Brand Equity sangat berkaitan dengan seberapa banyak pelanggan suatu merek merasa puas dan merasa rugi bila berganti merek (brand switching), menghargai merek itu dan menganggapnya sebagai teman, dan merasa terikat kepada merek itu (Kotler, 2007). Dengan demikian dapat dinyatakan bahwa ekuitas merek (brand equity) adalah kekuatan merek yang menjanjikan nilai yang diharapkan konsumen atas suatu produk sehingga akhirnya konsumen akan merasa mendapatkan kepuasan yang lebih bila dibanding produk-produk lainnya (McDonald, 2004).

Menurut Kotler (2007) ekuitas merek yang tinggi akan memberikan sejumah keunggulan bersaing bagi perusahaan, yaitu:

1) Perusahaan tersebut akan memiliki pengaruh perdagangan yang lebih besar dalam melakukan tawar menawar dengan distributor dan pengecer karena pelanggan mengharapkannya menjual merek tersebut.

2) Perusahaan tersebut dapat menggunakan harga yang lebih tinggi daripada pesaing-pesaingnya karena merek itu memiliki persepsi mutu untuk lebih tinggi.

3) Perusahaan tersebut dapat dengan mudah melakukan perluasan produk karena nama merek tersebut menyandang kredibilitas yang tinggi.

4) Merek tersebut menawarkan kepada perusahaan itu suatu pertahanan terhadap persaingan harga.

Brand equity tidak terjadi dengan sendirinya tetapi ditopang oleh elemen-elemen pembentuk brand equity, hal tersebut dapat dikelompokkan menjadi lima kategori (Durianto dkk., 2004), sebagai berikut:

1) Brand awareness atau kesadaran merek merupakan kesanggupan sekumpulan konsumen untuk mengenal atau mengingat kembali tentang keberadaan suatu merek yang merupakan suatu bagian dari kategori produk atau jasa tertentu. Hal ini ditunjukkan pada penelitian yang dilakukan oleh Romaniuk et al. (2004).

2) Brand Association atau asosiasi merek adalah pencitraan suatu merek terhadap suatu kesan tertentu dalam kaitannya dengan kebiasaan, gaya hidup, manfaat, atribut produk, geografi, harga, pesaing, selebritis dan lain-lain.
3) Brand Perceived quality atau persepsi kualitas merupakan persepsi konsumen terhadap kinerja kualitas atau keunggulan suatu produk atau jasa yang dibandingkan dengan harapan konsumen dalam mengkonsumsi produk atau jasa tersebut.

4) Brand loyalty atau loyalitas merek merupakan keterikatan atau kesetiaan konsumen dalam mengkonsumsi suatu merek produk atau jasa tertentu.

5) Other proprietary asset atau aset-aset merek lainnya.

Unsur-unsur brand equity diluar other proprietary asset dikenal dengan unsur-unsur utama dari brand equity. Elemen brand equity yang kelima (other proprietary asset) akan secara langsung dipengaruhi oleh kualitas dari keempat unsur utama tersebut. Hal ini juga sejalan dengan apa yang terungkap pada hasil penelitian Tuominen (1999) dan Fayrene \& Lee (2011).

Menurut Kotler \& Amstrong (2008) terdapat konsumen yang sadar akan keberadaan suatu produk atau jasa tertentu (brand awareness), kesadaran merek ini diukur berdasarkan ingatan atau pengakuan konsumen terhadap merek tersebut. Di atas itu, ada merek yang memiliki penerimaan (brand acceptability) yang tinggi atas suatu kondisi, konsumen tidak menolak untuk membeli merek tersebut. Kemudian ada pula merek yang tingkat preferensi mereknya tinggi, ini merupakan kondisi konsumen memilih suatu merek di atas merek lainnya. Akhirnya, terdapat merek yang memiliki tingkat kesetiaan merek yang tinggi dari konsumen.

Berdasarkan kajian teori, hasil penelitian sebelumnya dan rumusan masalah dari penelitian, maka hipotesis yang dirumuskan pada penelitian ini adalah sebagai berikut.

1) Terdapat perbedaan kesadaran merek (brand awareness) antara produk shampoo merek Sunsilk dengan produk shampoo merek Pantene.

2) Terdapat perbedaan asosiasi merek (brand association) antara produk shampoo merek Sunsilk dengan produk shampoo merek Pantene.

3) Terdapat perbedaan persepsi kualitas merek (brand perceived quality) antara produk shampoo merek Sunsilk dengan produk shampoo merek Pantene.

4) Terdapat perbedaan loyalitas merek (brand loyalty) antara produk shampoo merek Sunsilk dengan produk shampoo merek Pantene.

5) Terdapat perbedaan ekuitas merek (brand equity) antara produk shampoo merek Sunsilk dengan produk shampoo merek Pantene. 


\section{METODE PENELITIAN}

Penelitian ini dilakukan di empat kecamatan di Kota Denpasar, yaitu: Denpasar Barat, Denpasar Timur, Denpasar Utara dan Denpasar Selatan dengan distribusi tersebar. Subyek penelitian ini adalah masyarakat pengguna shampoo merek Pantene dan Sunsilk di Kota Denpasar.

Obyek penelitian ini adalah ekuitas merek (brand equity) dan elemen-elemennya yang terdiri atas kesadaran merek (brand awareness), asosiasi merek (brand association), persepsi kualitas merek (brand perceived quality) dan loyalitas merek (brand loyalty) produk shampoo merek Sunsilk dan Pantene pada pengguna kedua merek shampoo tersebut di Kota Denpasar.

Variabel yang digunakan dalam penelitian ini adalah brand equity (ekuitas merek) dengan sub variabel yang digunakan sebagai berikut: Brand Awareness (kesadaran merek); Brand association (asosiasi merek); Brand perceived quality (persepsi kualitas merek); Brand loyalty (loyalitas merek).

Variabel ekuitas merek (brand equity) pada penelitian ini didefinisikan sebagai nilai dari produk shampoo merek Sunsilk dan Pantene, menurut sejauh mana kedua merek itu mempunyai loyalitas merek yang tinggi, kesadaran nama, kualitas yang diterima dan asosiasi merek yang kuat. Sub variabel dalam penelitian ini didefinisikan, sebagai berikut:

1) Kesadaran merek (brand awareness) adalah kesanggupan untuk mengenal atau mengingat kembali tentang keberadaan produk (Durianto dkk., 2004) shampoo merek Sunsilk dan Pantene. Indikator-indikator (Roseviyanthi, 2011) yang digunakan adalah, sebagai berikut:

(a) Shampoo merek (Sunsilk/Pantene) adalah merek yang pertama kali muncul dalam benak saya ketika memikirkan sebuah merek shampoo.

(b) Shampoo merek (Sunsilk/Pantene) adalah merek yang pertama kali muncul dalam benak saya ketika hendak membeli shampoo.

(c) Saya telah mengenal Shampoo merek (Sunsilk/ Pantene) sebelumnya.

(d) Saya dengan mudah mengenali Shampoo merek (Sunsilk/Pantene) ketika melihat kemasannya.

(e) Saya dengan mudah mengenali Shampoo merek (Sunsilk/Pantene) ketika melihat tayangan iklannya di televisi.

2) Asosiasi merek (brand association) adalah keseluruhan kesan yang ada di benak konsumen yang berkenaan dengan ingatannya (Durianto dkk. 2004) terhadap produk shampoo merek Sunsilk dan Pantene. Indikator-indikator (Roseviyanthi, 2011) yang digunakan adalah, sebagai berikut: (a) Shampoo merek (Sunsilk/Pantene) adalah shampoo yang berasal dari perusahaan yang memiliki reputasi yang baik.

(b) Shampoo merek (Sunsilk/Pantene) adalah shampoo yang bebas bahan kimia berbahaya.

(c) Shampoo merek (Sunsilk/Pantene) adalah shampoo yang memiliki mutu yang baik.

(d) Shampoo merek (Sunsilk/Pantene) adalah shampoo yang sistem distribusinya baik.

(e) Shampoo merek (Sunsilk/Pantene) adalah shampoo yang memiliki kemasan yang paling menarik dibandingkan dengan kemasan shampoo merek lainnya.

3) Persepsi kualitas merek (brand perceived quality) adalah persepsi konsumen terhadap keseluruhan kualitas atau keunggulan (Durianto dkk. 2004) dari produk shampoo merek Sunsilk dan Pantene yang dikaitkan dengan harapan konsumen dalam mengkonsumsikan kedua produk tersebut. Indikator-indikator (Roseviyanthi, 2011) yang digunakan adalah, sebagai berikut:

(a) Menurut saya, Shampoo merek (Sunsilk/ Pantene) memiliki wangi yang lebih harum dibandingkan dengan shampoo merek lainnya.

(b) Menurut saya, Shampoo merek (Sunsilk/ Pantene) memberikan hasil yang lebih baik bagi rambut ditiap-tiap jenis masalah rambut dibandingkan dengan shampoo merek lainnya.

(c) Menurut saya, harga Shampoo merek (Sunsilk/ Pantene) sesuai dengan kualitas yang dihasilka nnya.

(d) Menurut saya, Shampoo merek (Sunsilk/ Pantene) paling mudah didapat.

(e) Menurut saya, Shampoo merek (Sunsilk/ Pantene) paling berkualitas.

4) Loyalit as merek (brand loyalty) adalah ukuran kesetiaan konsumen (Rangkuti, 2002) terhadap produk shampoo merek Sunsilk dan Pantene. Indikator-indikator (Roseviyanthi, 2011) yang digunakan adalah sebagai berikut.

(a) Saya ingin mencoba shampoo merek lain selain shampoo merek (Sunsilk/Pantene).

(b) Saya menggunakan Shampoo merek (Sunsilk/ Pantene) karena sudah menjadi kebiasaan.

(c) Saya menggunakan Shampoo merek (Sunsilk/ Pantene) karena sudah merasa puas.

(d) Saya tidak akan membeli shampoo merek lain jika shampoo merek (Sunsilk/Pantene) tidak tersedia di tempat saya berbelanja.

(e) Saya merasa rugi jika saya menggunakan shampoo merek lain selain Shampoo merek (Sunsilk/Pantene).

Populasi dalam penelitian ini adalah konsumen shampoo merek Pantene dan Sunsilk yang ada di Kota Denpasar. Sampel dalam penelitian ini ditentu- 
kan dengan teknik non-probability sampling. Teknik non-probability sampling digunakan karena jumlah populasi dalam penelitian ini tidak diketahui. Jumlah anggota sampel pada penelitian ini ditentukan berdasarkan oleh teori yang menyatakan bahwa jumlah sampel dalam penelitian dapat ditentukan dengan perhitungan lima sampai sepuluh kali dari jumlah indikator variabel yang diteliti (Sarmanu, 2003). Indikator variabel yang digunakan dalam penelitian ini adalah sebanyak 20 indikator variabel, sehingga banyak responden sebagai sampel antara 100 hingga 200 orang responden.

Teknik non-probability sampling yang digunakan dalam penelitian ini adalah teknik purposive sampling, yang mana metode ini merupakan prosedur sampling yang memilih sampel dari orang atau unit yang dijumpai atau diakses dengan pertimbangan tertentu (Sugiyono, 2012). Pertimbangan yang digunakan dalam memilih responden adalah konsumen yang membeli shampoo untuk keramas lebih dari tiga kali, sampai penelitian ini dilakukan dengan umur responden minimal 17 tahun dengan tingkat pendidikan terakhir minimal Sekolah Menengah Pertama (SMP). Memilih responden dengan umur minimal 17 tahun adalah dengan mempertimbangkan bahwa responden dengan umur 17 tahun sudah dapat memberikan pendapat dan menjawab pertanyaan penelitian secara rasional.

Metode pengumpulan data pada penelitian ini adalah sebagai berikut: 1) Metode dokumentasi dilakukan dengan cara memperoleh data dari bukubuku referensi dan jurnal, mencari informasi langsung pada internet serta majalah dan tabloid yang berhubungan dengan penelitian; 2) Metode survey digunakan untuk memperoleh informasi dari responden melalui pertanyaan-pertanyaan yang mengungkap tentang brand equity Sunsilk dan Pantene. Pertanyaan yang digunakan adalah pertanyaan tertutup. Pertanyaan-pertanyaan dalam kuesioner berdasarkan pada Skala Likert (skala 1 sampai 5), dengan ketentuan penilaian masing-masing alternatif jawaban sebagai berikut: (a) Jawaban Sangat Setuju (SS) diberi skor 5; (b) Jawaban Setuju (S) diberi skor 4; (c) Jawaban Cukup Setuju (CS) diberi skor 3; (4) Jawaban Tidak Setuju (TS) diberi skor 2; (e) Jawaban Sangat Tidak Setuju (STS) diberi skor 1

Pembuktian hipotesis komparatif dilakukan dengan menggunakan uji beda mean. Penelitian komparatif ini menggunakan Uji beda mean untuk sampel berpasangan (paired sample). Menurut Santoso \& Tjiptono (2001) sampel berpasangan (paired sample) adalah sampel dengan subyek yang sama namun mengalami dua perlakuan atau pengukuran yang berbeda. Uji beda mean dilakukan dengan menggunakan alat bantu SPSS for Windows 17.00. Pengambilan keputusan yang dijadikan acuan adalah jika probabilitas atau signifikannya (sig. 2 tailed) < 0,05, maka hipotesis yang menyatakan terdapat perbedaan antara brand equity produk shampoo merek Sunsilk dan Pantene bagi penduduk di Kota Denpasar dapat diterima.

\section{HASIL PENELITIAN DAN PEMBAHASAN}

Karakteristik responden pada penelitian ini dapat dilihat pada Tabel 1.

\section{Tabel 1. Karakteristik Responden}

\begin{tabular}{|c|c|c|c|c|}
\hline No. & $\begin{array}{c}\text { Karakteristik } \\
\text { Responden }\end{array}$ & Keterangan & $\begin{array}{l}\text { Jumlah } \\
\text { (orang) }\end{array}$ & $\begin{array}{c}\text { Persentase } \\
(\%)\end{array}$ \\
\hline \multirow{2}{*}{\multicolumn{2}{|c|}{ 1. Jenis Kelamin }} & Laki-laki & 45 & 37,5 \\
\hline & & Perempuan & 75 & 62,5 \\
\hline \multicolumn{3}{|c|}{ JUMLAH } & 120 & 100 \\
\hline \multirow{4}{*}{\multicolumn{2}{|c|}{ 2. Usia }} & $17-26$ & 72 & 60 \\
\hline & & $27-36$ & 25 & 20,8 \\
\hline & & $37-46$ & 11 & 9,2 \\
\hline & & $>46$ & 12 & 10 \\
\hline \multicolumn{3}{|c|}{ JUMLAH } & 120 & 100 \\
\hline \multirow{5}{*}{\multicolumn{2}{|c|}{$\begin{array}{l}\text { 3. Pendidikan } \\
\text { Terakhir }\end{array}$}} & SMP & 5 & 4,2 \\
\hline & & SMA/SMK & 59 & 49,2 \\
\hline & & Diploma & 13 & 10,8 \\
\hline & & Sarjana & 40 & 33,3 \\
\hline & & Pascasarjana & 3 & 2,5 \\
\hline \multicolumn{3}{|c|}{ JUMLAH } & 120 & 100 \\
\hline \multirow{6}{*}{\multicolumn{2}{|c|}{$\begin{array}{l}\text { 4. } \text { Rutinitas } \\
\text { yang dilakukan }\end{array}$}} & $\begin{array}{l}\text { Siswa / } \\
\text { Mahasiswa }\end{array}$ & 51 & 42,5 \\
\hline & & PNS & 15 & 12,5 \\
\hline & & Pegawai & 42 & 35 \\
\hline & & Swasta & & \\
\hline & & Wiraswasta & 8 & 6,7 \\
\hline & & Lain-lain & 4 & 3,3 \\
\hline \multicolumn{3}{|c|}{ JUMLAH } & 120 & 100 \\
\hline
\end{tabular}

Berdasarkan Tabel 1 dapat dilihat bahwa berdasarkan jenis kelamin, responden terbanyak adalah perempuan dengan jumlah 75 orang dan laki-laki 45 orang, sedangkan pengelompokan berdasarkan usia, jumlah tertinggi yaitu pada usia 17-26 tahun sebanyak 72 orang, diikuti oleh usia 27-36 tahun sebanyak 25 orang, kemudian usia lebih dari 46 tahun sebanyak 12 orang dan jumlah terendah adalah usia 37-46 tahun sebanyak 11 orang. Hal ini berarti pengguna shampoo yang diteliti lebih banyak yang berusia 17-26 tahun daripada yang berusia 37-46 tahun.

Berdasarkan pengelompokan pendidikan terakhir, jumlah tertinggi berada pada pendidikan SMA/SMK sebanyak 59 orang, diikuti oleh pendidikan Sarjana sebanyak 40 orang, kemudian pendidikan Diploma sebanyak 13 orang, pendidikan 
SMP sebanyak 5 orang, diikuti dengan pendidikan Pascasarjana sebanyak 3 orang. Ini berarti pengguna shampoo yang diteliti adalah sebagian besar berpendidikan SMA/SMK.

Dari penelitian juga diperoleh hasil mengenai konsistensi konsumen dalam menggunakan produk shampoo. Hal tersebut ditunjukkan pada Tabel 2.

Tabel 2. Konsistensi Penggunaan Produk Shampoo

\begin{tabular}{lcc}
\hline Konsistensi & Jumlah (Orang) & Presentase (\%) \\
\hline Tidak pernah & 0 & 0 \\
Jarang & 81 & 67,5 \\
Sering & 29 & 24,2 \\
Sangat sering & 10 & 8,3 \\
\hline JUMLAH & $\mathbf{1 2 0}$ & $\mathbf{1 0 0}$ \\
\hline
\end{tabular}

Berdasarkan Tabel 2 diketahui bahwa konsumen yang menjawab jarang berganti produk shampoo adalah yang paling banyak, yaitu sebesar 81 orang, diikuti oleh konsumen yang menjawab sering berganti produk shampoo yaitu sebanyak 29 orang, konsumen yang menjawab sangat sering berganti produk shampoo sebanyak 10 orang, sedangkan tidak terdapat konsumen yang menjawab tidak pernah berganti produk shampoo. Ini berarti, konsumen cukup konsisten dalam menggunakan produk shampoo yang telah sesuai ataupun mendekati harapan konsumen.

\section{Perbandingan Kesadaran Merek (Brand Awareness)}

Sebelum dilakukan uji beda mean, skala jawaban responden pada masing-masing indikator sub variabel kesadaran merek dirata-ratakan terlebih dahulu untuk mengetahui rata-rata jawaban masingmasing responden pada sub variabel kesadaran merek. Kemudian, dilakukan uji beda mean dengan sampel berpasangan (paired sample). Hasil yang diperoleh adalah pada Tabel 3.

Tabel 3. Hasil uji beda means pada sub-variabel Brand Awareness

\begin{tabular}{cccc}
\hline Subvariabel & Means & $\begin{array}{c}\text { Paired } \\
\text { Differences } \\
\text { Means }\end{array}$ & Sig. (2-tailed) \\
\cline { 1 - 2 } S.aware & 2,833 & 0,0367 & 0,559 \\
\hline P.aware & 2,797 & 0,037 & \\
\hline
\end{tabular}

Berdasarkan Tabel 3 dapat dilihat bahwa ratarata kesadaran merek (brand awareness) produk shampoo Sunsilk sebesar 2,833 lebih besar jika dibandingkan dengan rata-rata kesadaran merek (brand awareness) produk shampoo Pantene yang sebesar 2,797 dengan perbedaan rata-ratanya sebesar
0,0367 . Probabilitasnya lebih besar dari 0,05 . Dengan demikian, tidak terdapat perbedaan antara kesadaran merek (brand awareness) produk shampoo Sunsilk dengan produk shampoo Pantene, yang mana konsumen sama-sama sadar akan keberadaan merek produk shampoo Sunsilk dan Pantene. Hal ini dikarenakan shampoo Sunsilk maupun shampoo Pantene sama-sama gencar melakukan berbagai kegiatan promosi sehingga brand awareness-nya sama-sama tinggi. Hasil penelitian ini didukung oleh hasil penelitian sebelumnya yang dilakukan oleh Makerti (2010).

Jawaban keseluruhan responden untuk setiap indikator variabel brand awareness baik pada produk shampoo Sunsilk maupun Pantene memiliki modus jawaban pada angka 4. Hal ini berarti konsumen merasa cukup baik dalam mengenal produk shampoo Sunsilk maupun Pantene.

\section{Perbandingan Asosiasi Merek (Brand Association)}

Sebelum dilakukan uji beda mean, skala jawaban responden pada masing-masing indikator sub variabel asosiasi merek dirata-ratakan terlebih dahulu untuk mengetahui rata-rata jawaban masing-masing responden pada sub variabel asosiasi merek. Kemudian, dilakukan uji beda mean dengan sampel berpasangan (paired sample). Hasil yang diperoleh adalah pada Tabel 4 .

Tabel 4. Hasil uji beda means pada sub-variabel Brand Association

\begin{tabular}{cccc}
\hline Subvariabel & Means & $\begin{array}{c}\text { Paired } \\
\text { Differences } \\
\text { Means }\end{array}$ & Sig. (2-tailed) \\
\cline { 1 - 2 } S.association & 2,828 & $-0,0267$ & 0,521 \\
\hline P.association & 2,855 & -257 & \\
\hline
\end{tabular}

Berdasarkan Tabel 4 dapat dilihat bahwa ratarata asosiasi merek (brand association) produk shampoo Sunsilk sebesar 2,828 lebih kecil jika dibandingkan dengan rata-rata asosiasi merek (brand association) produk shampoo Pantene sebesar 2,855 dengan perbedaan rata-ratanya sebesar 0,0267. Probabilitasnya lebih besar dari 0,05. Dengan demikian, tidak terdapat perbedaan antara asosiasi merek (brand association) produk shampoo Sunsilk dengan Pantene, yang mana konsumen menganggap merek produk shampoo Pantene memiliki asosiasi merek produk yang sama, yaitu sama-sama diproduksi oleh perusahaan yang memiliki reputasi baik yang telah memproduksi shampoo dengan mutu yang baik. Hasil penelitian ini didukung oleh hasil penelitian sebelumnya yang dilakukan oleh Makerti (2010), Chen (2001). 
Jawaban keseluruhan responden untuk setiap indikator variabel brand association baik pada produk shampoo merek Sunsilk maupun Pantene memiliki modus jawaban pada angka 4. Hal ini berarti konsumen menganggap bahwa produk shampo merek Sunsilk dan Pantene cukup berhasil dalam mengasosiasikan mereknya dengan citra produk yang ingin ditanamkan di benak konsumen.

\section{Perbandingan Persepsi Kualitas Merek (Brand Perceived Quality)}

Sebelum dilakukan uji beda mean skala jawaban responden pada masing-masing indikator sub variabel persepsi kualitas merek dirata-ratakan terlebih dahulu untuk mengetahui rata-rata jawaban masing-masing responden pada sub variabel persepsi kualitas merek. Kemudian, dilakukan uji beda mean dengan sampel berpasangan (paired sample). Hasil yang diperoleh adalah pada Tabel 5 .

Tabel 5. Hasil uji beda mean pada sub variabel Brand Perceived Quality

\begin{tabular}{cccc}
\hline Subvariabel & Means & $\begin{array}{c}\text { Paired } \\
\text { Differences } \\
\text { Means }\end{array}$ & Sig. (2-tailed) \\
\cline { 1 - 2 } S.perceived & 2,580 & $-0,1417$ & 0,023 \\
\hline P.perceived & 2,722 & & \\
\hline
\end{tabular}

Berdasarkan Tabel 5 dapat dilihat bahwa ratarata persepsi kualitas merek (brand perceived quality) produk shampoo Sunsilk sebesar 2,580 lebih kecil jika dibandingkan dengan rata-rata persepsi kualitas merek (brand perceived quality) produk shampoo Pantene yaitu sebesar 2,722 dengan perbedaan rataratanya 0,1417. Probabilitas lebih kecil dari 0,05. Dengan demikian, terdapat perbedaaan antara persepsi kualitas merek (brand perceived quality) produk shampoo merek Sunsilk dengan Pantene, yang mana persepsi konsumen terhadap keseluruhan kualitas merek produk shampoo merek Pantene lebih mendekati harapan konsumen dibandingkan produk shampoo merek Sunsilk. Konsumen menganggap produk shampoo Pantene memiliki aroma yang lebih wangi dibandingkan dengan shampoo Sunsilk, serta kandungan shampoo Pantene yang dapat memberikan hasil yang lebih baik bagi tiap-tiap jenis masalah rambut dibandingkan dengan shampoo merek Sunsilk. Perbedaan persepsi kualitas merek shampo Sunsilk dengan shampo Pantene adalah signifikan. Hasil penelitian ini didukung oleh hasil penelitian sebelumnya yang dilakukan oleh Roseviyanthi (2011), Makerti (2010), Jung \& Sung (2008), serta Darwing \& Wijoyo (2004).
Jawaban keseluruhan responden untuk setiap indikator variabel brand perceived quality baik pada produk shampoo Sunsilk dengan shampoo Pantene memiliki modus jawaban pada angka 4. Hal ini berarti konsumen menganggap bahwa produk shampoo merek Sunsilk maupun Pantene memiliki persepsi keseluruhan kualitas yang baik sesuai dengan harapan konsumen akan produk tersebut.

\section{Perbandingan Loyalitas Merek (Brand Loyalty)}

Sebelum dilakukan uji beda mean, skala jawaban responden pada masing-masing indikator sub variabel loyalitas merek dirata-ratakan terlebih dahulu untuk mengetahui rata-rata jawaban masing-masing responden pada sub variabel loyalitas merek. Kemudian, dilakukan uji beda mean dengan sampel berpasangan (paired sample). Hasil yang diperoleh adalah pada Tabel 6 .

Tabel 6. Hasil uji beda mean pada sub variabel Brand Loyalty

\begin{tabular}{cccc}
\hline Subvariabel & Means & $\begin{array}{c}\text { Paired } \\
\text { Differences } \\
\text { Means }\end{array}$ & Sig. (2-tailed) \\
\hline S.loyalty & 2,420 & $-0,0567$ & 0,347 \\
\hline P.loyalty & 2,477 & & \\
\hline
\end{tabular}

Berdasarkan Tabel 6 dapat dilihat bahwa ratarata loyalitas merek (brand loyalty) produk shampoo Sunsilk sebesar 2,420 lebih kecil jika dibandingkan dengan rata-rata loyalitas merek (brand loyalty) produk shampoo Pantene sebesar 2,477 dengan perbedaan rata-ratanya 0,0567 . Probabilitas lebih besar dari 0,05. Dengan demikian, tidak terdapat perbedaan antara loyalitas merek (brand loyalty) produk shampoo Sunsilk dengan Pantene, yang mana konsumen memiliki kesetiaan (loyalitas) yang sama terhadap produk shampoo merek Pantene maupun shampo merek Sunsilk. Hal ini dikarenakan produk shampoo Pantene dianggap sama dalam mengatasi masalah-masalah rambut dengan produk shampoo Sunsilk dan memberikan kepuasan yang hampir mirip. Hasil penelitian ini didukung oleh hasil penelitian sebelumnya yang dilakukan oleh Robertus (2007)

Jawaban keseluruhan responden untuk setiap indikator variabel brand loyalty pada produk shampoo merek Sunsilk dan merek Pantene memiliki modus jawaban pada angka 2. Hal ini berarti kesetiaan (loyalitas) konsumen pada produk shampoo merek Sunsilk dan Pantene kurang baik. Hal yang kurang mendapat kesetiaan konsumen pada produk shampoo merek Sunsilk dan Pantene adalah apabila 
produk tersebut tidak tersedia di tempat konsumen berbelanja, maka konsumen akan membeli shampoo merek lain yang tersedia. Selain itu, konsumen tidak merasa rugi jika menggunakan shampoo merek lain, selain merek Sunsilk dan Pantene.

\section{Perbandingan Ekuitas Merek (Brand Equity)}

Sebelum dilakukan uji beda mean, skala ratarata sub variabel ekuitas merek yang terdiri dari kesadaran merek, asosiasi merek, persepsi kualitas merek dan loyalitas merek dirata-ratakan kembali untuk diperoleh hasil rata-rata ekuitas merek per masing-masing produk. Kemudian, dilakukan uji beda mean dengan sampel berpasangan (paired sample). Hasil yang diperoleh adalah pada Tabel 7.

Tabel 7. Hasil uji beda mean pada variabel Brand Equity

\begin{tabular}{cccc}
\hline $\begin{array}{c}\text { Sub- } \\
\text { variabel }\end{array}$ & Means & $\begin{array}{c}\text { Paired } \\
\text { Differences } \\
\text { Means }\end{array}$ & Sig. (2-tailed) \\
\cline { 1 - 2 } S.equity & 2,665 & & $-0,0470$ \\
\hline P.equity & 2,712 & 0,333 \\
\hline
\end{tabular}

Berdasarkan Tabel 7 dapat dilihat bahwa ratarata ekuitas merek (brand equity) produk shampoo Sunsilk sebesar 2,665 lebih kecil jika dibandingkan dengan rata-rata ekuitas merek (brand equity) produk shampo Pantene sebesar 2,712 dengan perbedaan rata-ratanya sebesar 0,0470 . Probabilitas lebih besar dari 0,05. Dengan demikian, tidak terdapat perbedaan antara produk shampoo Sunsilk dengan produk shampoo Pantene. Hal ini disebabkan karena dari empat dimensi brand equity hanya satu dimensi yaitu brand perceived quality yang berbeda secara signifikan, sedangkan tiga dimensi, yaitu brand awareness, brand association, dan brand loyalty tidak ada perbedaan secara signifikan. Hasil penelitian ini didukung oleh hasil penelitian sebelumnya yang dilakukan oleh Makerti (2010), tetapi tidak searah dengan hasil penelitian yang dilakukan oleh (Gupta \& Verma 2008) yang menunjukkan hasil bahwa ekuitas merek dari dua produk telepon berbeda secara signifikan.

Jawaban keseluruhan responden untuk setiap indikator variabel brand equity baik pada produk shampoo merek Sunsilk dengan Pantene memiliki skor rata-rata 4. Hal ini berarti secara keseluruhan produk shampoo merek Sunsilk dan Pantene memiliki kekuatan merek yang menjanjikan nilai yang cukup baik pada konsumen.

\section{SIMPULAN DAN SARAN}

Berdasarkan hasil pembahasan, dapat ditarik beberapa simpulan sebagai berikut: Dari empat dimensi brand equity, terdapat tiga dimensi, yaitu: brand awareness, brand association, dan brand loyalty tidak menunjukkan perbedaan yang signifikan antara shampoo merek Sunsilk dengan Pantene. Tidak adanya perbedaan pada dimensi brand awareness disebabkan karena kedua merek shampoo tersebut sama-sama gencar melakukan promosi sehingga kesadaran pasar terhadap kedua merek tersebut juga sama-sama tinggi. Demikian juga pada dimensi brand association tidak menunjukkan perbedaan, karena kedua shampoo tersebut diproduksi oleh perusahaan yang sudah terkenal dan punya citra baik, dan pada dimensi brand loyalty juga tidak menunjukkan perbedaan karena kedua shampoo merupakan produk kebutuhan sehari-hari yang mana perilaku konsumen terhadap produk konvenien tidak tinggi. Hanya satu dimensi yang menunjukkan perbedaan signifikan yaitu brand perceived quality, di mana hal ini disebabkan karena kualitas dari kedua shampoo tersebut seperti aromanya, wanginya memang menunjukkan perbedaan. Secara keseluruhan brand equity juga tidak menunjukkan perbedaan yang signifikan. Hal ini disebabkan karena dari empat dimensi hanya satu dimensi yang berbeda signifikan.

Berdasarkan hasil analisis dan simpulan yang diperoleh, maka saran yang dapat diberikan adalah sebagai berikut: Sunsilk yang dipersepsikan konsumen lebih rendah kualitasnya seharusnya terus melakukan inovasi produk, terutama pada aromanya dan kandungan bahan yang tertera di label kemasannya. Untuk itu ke depan shampoo merek Sunsilk perlu lebih berorientasi pada litbangnya agar mampu menyamai atau melebihi inovasi shampoo merek Pantene. Untuk dapat meningkatkan persepsi kualitas merek tersebut dapat dilakukan pengembangan produk untuk menghasilkan produk yang berkualitas dan sesuai dengan keinginan konsumen; Berdasarkan hasil penelitian terdapat beberapa faktor yang dipertimbangkan dalam melakukan pembelian shampoo. Produsen produk shampoo merek Sunsilk dan Pantene hendaknya memperhatikan bahan atau kandungan yang digunakan pada produk shampoo yang dihasilkan sehingga manfaat shampoo dapat dirasakan oleh konsumen sesuai dengan keinginan dan kebutuhan konsumen. Akan tetapi, faktor lain seperti harga, kemasan, sistem distribusi, bebas bahan kimia berbahaya, iklan, aroma/wangi shampoo serta promosi tidak dapat diabaikan karena dapat pula menjadi keunggulan kompetitif (competitive advantage) dari merek tersebut. 


\section{DAFTAR REFERENSI}

Bodet, G. \& Chanavat, N. 2010. Building Global Football Brand Equity: Lessons from the Chinese Market. Asia Pacific Journal of Marketing and Logistics, 22(1): 55-66.

Chen, A. C. H. 2001. Using Free Association to Examine the Relationship Between the Characteristics of Brand Associations and Brand Equity. Journal of Product \& Brand Management, 10(7): 439-451.

Cuomo, M. T., Metallo, G., Tortora, D., Testa, M. \& Kitchen, P. J. 2009. Building Brand Equity: The Genetic Coding of Mediterranean Brands. EuroMed Journal of Business, 4(3): 237-253.

Darwing \& Wijoyo, S. 2004. Analisis Komparasi Ekuitas Merek Ades dan Merek Aqua di Kalangan Mahasiswa di Surabaya, Skripsi tidak dipublikasi Fakultas Ekonomi Universitas Kristen Petra, Surabaya.

Daulay, F. A. 2006. Analisis Perbandingan ElemenElemen Ekuitas Merek Pada Supermarket Macan dan Maju Bersama di Kota Medan Sebagai Salah Satu Strategi Dalam Menentukan Keputusan Pemasaran. Jurnal Sistem Teknik Industri, 7(2): 53-60.

Davis, D. F., Golicic, S. L. \& Marquardt, A. 2009. Measuring Brand Equity for Logistics Services. The International Journal of Logistics Management, 20(2): 201-212.

Delgado-Ballester, E. \& Munuera-Alemán, J. L. 2005. Does Brand Trust Matter to Brand Equity? Journal of Product \& Brand Management, 14(3): 187-196.

Durianto, D., Sugiarto \& Sitinjak, T. 2004. Strategi Menaklukkan Pasar Melalui Riset Ekuitas dan Perilaku Merek. Jakarta: PT Gramedia Pustaka Utama.

Eugenia, I. 2011. The Power of Top Brand. Majalah Marketing. pp. 27-34.

Fayrene \& Lee, G. C. 2011. Customer-based Brand Equity: A Literature Review. Journal of Arts Science \& Commerce, 11(1): 33-42.

Frontier Consulting Group. 2011. Top Brand Index, http://www.frontier.co.id, (diakses 1 April 2013).

Gupta, N. \& Verma, P. 2008. Comparative Brand Equity of Hutch and Airtel Cell Phone (Delhi). The Requirement of Bachelor of Business Administration (BBA).

Heruwati, E. 2010. Analisis Pengaruh Daya Tarik, Kreadibilitas, dan Keahlian Celebrity Endorser terhadap Keputusan Pembelian Sepeda Motor Yamaha Mio. Skripsi tidak dipublikasi pada Program Sarjana Fakultas Ekonomi Universitas Diponegoro, Semarang.
Jung, J. \& Sung, E. Y. 2008. Consumer-Based Brand Equity: Comparisons Among Americans and South Koreans in the USA and South Koreans in Korea. Journal of Fashion and Management, 12(1): 24-35.

Kartajaya, H. 2004. Hermawan Kartajaya on Brand. Bandung: Mizan Pustaka.

Kartono, 2007. Analisis Elemen-elemen Ekuitas Merek Produk Minyak Pelumas Motor Merek Enduro $4 T$ (Studi Kasus Pada Mahasiswa Universitas Negeri Semarang). Skripsi tidak dipublikasi pada Fakultas Ekonomi Universitas Negeri Semarang.

Keller, K. L. 2005. Measuring Brand Equity. Journal of Marketing and Management. 12(2): 271-288.

Kimpakorn, N. \& Tocquer, G. 2010. Service Brand Equity and Employee Brand Commitment. Journal of Services Marketing, 24(5): 378-388.

Kotler, P. 2007. Manajemen Pemasaran. Edisi Kesebelas. Jakarta: PT Indeks Kelompok Gramedia.

Kotler, P. \& Amstrong, G. 2008. Prinsip-Prinsip Pemasaran. Edisi Kedelapan. Jilid 1. Jakarta: Erlangga.

Laboy, P. 2007. The Importance of Measuring Brand Value and Brand Equity. Virginia: George Mason University Publisher.

Makerti, I. A. A. 2010. Analisis Perbandingan Brand Equity Produk Penyedap Rasa Royco Dengan Produk Penyedap Rasa Masako (Studi Kasus Pada Ibu Rumah Tangga di Kota Denpasar). Skripsi tidak dipublikasi pada Fakultas Ekonomi Universitas Udayana, Denpasar.

Marthin, J. \& Semuel, H. 2007. Analisis Tingkat Brand Loyalty pada Produk Shampoo Merek "Head \& Shoulders". Jurnal Manajemen Pemasaran, 2(2): 90-101.

McDonald, S. S. 2004. Brand Equity: Working Toward A Diciplined Methodology for Measurement. Journal of Brand and Measurement, 1(2): 2-9.

Monalisa \& Fitra, S. 2011. Unilever dan $P \& G$ Kuasai 90\% Pangsa Pasar Sampo Indonesia, http://www.indonesiafinancetoday.com, (diakses 1 April 2013).

Mourad, M., Ennew, E. \& Kortam, W. 2011. Brand Equity in Higher Education. Marketing Intelligence \& Planning, 29(4): 403-420.

Pappu, R. \& Quester, P. G. 2008. Does Brand Equity Vary Between Department Stores and Clothing Stores? Results of an Empirical Investigation. Journal of Product \& Brand Management, 17(7): 425-435.

Pinar, M., Girard, T. \& Eser, Z. 2012. Consumerbased Brand Equity in Banking Industry: A Comparison of Local and Global Banks in 
Turkey. International Journal of Bank Marketing, 30(5): 359-375.

Quarles, R. C. 2009. A Conceptual and Measurement Model for Brand Equity Research, http://www. qsaresearch.com/images/equity.pdf, (diakses 10 April 2012).

Rangkuti, F. 2002. Measuring Customer Satisfaction Teknik Mengukur dan Strategi Meningkatkan Kepuasan Pelanggan dan Analisis Kasus PLN$J P$. Jakarta: PT Gramedia Pustaka Utama.

Robertus, S. A. 2007. Analisis Perbandingan Brand Equity Indomie dengan Mie Sedaap (Studi Kasus Pada Mahasiswa Universitas Negeri Semarang). Skripsi tidak dipublikasi pada Fakultas Ekonomi Universitas Negeri Semarang, Semarang.

Romaniuk, J., Sharp, B., Paech, S. \& Driesener, C. 2004. Brand and Advertising Awareness: A Replication and Extension of a Known Empirical Generalisation. Australasian Marketing Journal, 12(3): 70-80.

Roseviyanthi, R. 2011. Analisis Perbandingan Brand Equity Produk Mie Instant Merek Indomie dengan Produk Mie Instant Merek Mie Sedaap (Studi Kasus Pada Penduduk di Kota Denpasar). Skripsi tidak dipublikasi pada Fakultas Ekonomi Universitas Udayana, Denpasar.

Rajat, R. \& Chau, R. 2011. Consumer-based Brand Equity and Status-Seeking Motivation for a Global Versus Local Brand. Asia Pacific Journal of Marketing and Logistics, 23(3): 270 284.

Santoso, F. 2010. Studi tentang Loyalitas Merek (Kasus pada Shampoo Sunsilk di Kota Semarang). Tesis tidak dipublikasi pada Program Studi Magister Manajemen Universitas Diponegoro. Semarang.
Santoso, S. \& Tjiptono, F. 2001. Konsep dan Aplikasi SPSS. Jakarta: PT Elex Media Komputindo.

Santoso, Y. \& Resdianto, R. 2007. Brand sebagai Kekuatan Perusahaan dalam Persaingan Global. Business and Management Journal Bunda Mulia, 3(2): 52-63.

Sanyal, S. N. \& Datta, S. K. 2011. The Effect of Country of Origin on Brand Equity: An Empirical Study on Generic Drugs. Journal of Product \& Brand Management, 20(2): 130 140.

Sarmanu, H. 2003. Materi Penelitian Structural Equation Modelling (Permodelan Persamaan Struktural). Diktat Kuliah Lembaga Penelitian Universitas Airlangga, Surabaya.

Schumann, D. W. 2004. The Comparative Ordered Influence of Brand Equity's Experiential and Functional Antecedents and Dimensions, and Its Consequences on U.S. and Mainland Chinese Consumers. Journal of Brand and Management, 1(1): 311-344.

Smith, D. 2007. An Analysis of Brand Equity Determinants: Gross Profit, Advertising, Research, and Development. Journal of Business \& Economics Research, 5(11): 103-116.

Sugiyono. 2012. Metode Penelitian Bisnis. Bandung: Alfabeta.

Tuominen, P. 1999. Managing Brand Equity. LTA, 1: 65-100.

Wang, W. T. \& Li, H. M. 2012. Factors Influencing Mobile Services Adoption: A Brand-Equity Perspective. Internet Research, 22(2): 142-179.

Wood, L. 2000. Brands and Brand Equity: Definition and Management. Management Decision, 38(9): 662-669. 